\title{
Paperless, Optimized and Intelligent Business by Using Successful Business Process Management Concepts
}

\author{
Emir Zunic ${ }^{1}$, Almir Djedovic ${ }^{1}$ and Bahira Zunic ${ }^{2}$ \\ 1. Info Studio Ltd Sarajevo, Sarajevo 71000, Bosnia and Herzegovina \\ 2. Goethe-Institut Sarajevo, Sarajevo 71000, Bosnia and Herzegovina
}

\begin{abstract}
This paper presents a practical usage of several business process management concepts, technologies and tools in the example of the business process for banking payments system. Seen from one perspective, the actual trend in business management is the transfer from functional to process approach. Process approach is considered as a key tool for improvement of business processes. Implementation of process principles into management brings a lot of changes with positive effects as higher competitiveness, productivity and performance of enterprise are. Seen from another perspective many organizations are taking steps to reduce the amount of paper in their business processes. The trend is particularly strong in the financial services industry, where paper-intensive processes present stringent regulatory requirements for timely processing and for controlling the flow of the documents associated with these processes. In this paper is shown how can the process in financial service industry be improved using these two concepts. First step is to integrate BPM (business process management) and DMS (document management system) and results are monitored using BI (business intelligence) and BAM (business activity monitoring). Time, cost and human resources results before and after the usage of this complex system will be also presented.
\end{abstract}

Key words: Business process management, document management system, business intelligence, banking payments system, industrial system.

\section{Introduction}

Business processes are at the heart of business operations. For decades business process management was limited to only the ability to document processes. As the means to document processes technologically improved so did the potential to use technology to manage more aspects of the process. Over the years vendor specialists built tools to simplify a subset of the overall complex process like workflow, or enterprise application integration. Business process management suite software introduced the promise of a comprehensive solution to manage all enterprise processes and to do so with greater efficiency. Solutions offered greater process management capabilities than ever before but fell short of delivering on the promise of a truly integrated and complete business process management suite. Process

Corresponding author: Emir Zunic, M.Sc., research fields: data mining, big data, business process management. management success was constrained, as a result, by an artificial set of barriers that resulted in the continuing need for multiple process management products in the enterprise. This added complexity, time, and cost which reduced the effectiveness of this important technology [1].

In today's economy, which under the influence of globalization expands its markets, but also gets the competitions closer, numerous companies strive to find the ways for increasing the efficiency and reducing the operating costs. The acceptance of the process approach as the key element of business comes as a result of all these. Process orientation helps companies in considering their activities and assignments to add or subtract value for the consumers [2] and also adds to organizational structures a new dimension of complexity. The importance of process orientation is best reflected in the conclusion of consulting firm Gartner: "Business 
process management wins the triple crown: for time saving, money saving and value adding” [3]. It also expands its business and points to the importance of technology during the creating strategy, which provides a competitive advantage. Finally, process management provides company the short-term return on investments, as well as long-term invested capital value.

Today's organizations face increasing business pressures due to globalization, changing competitors, stricter regulations, faster pace of innovation, and demand for better customer service. Trends such as mobile, social, cloud, and analytics have a profound impact on a company's business and its core business processes. Companies expect business driven rapid process automation, seamless collaboration among all stakeholders, deep insights for better business decisions, unprecedented agility and operational excellence.

In global competition in the market, companies may achieve the competitive superiority only by offering cheaper and more qualitative products and services, and for the realization of those intents, they need efficient and innovative business processes. Although the projects with the aim of changing the companies' business are not uncommon, relatively small number of companies successfully carries them out. Studies have shown that for the successful implementation of business changes projects, the application of appropriate software tools for business process modeling and business process management is of a great importance. The development of an integrated model of business processes enables the documentation, analysis, standardization and improvement of business processes. Integration of organizational knowledge (business rules, procedures, standards and best practice) in model of business process creates the repository of knowledge as the basis for the development of knowledge management system in the company. There are numerous tools for business process management and knowledge in the company. Decision of the selection of optimal software tool depends on the quality and capability of the tools, as well as of the objectives of business project change. In the example of business process being implemented in the bank, Oracle BPMS (business process management suite) was used, which is the world leading tool in this sphere according to many indicators.

This paper describes the role of Intelligent Business Process Management for industrial purposes in more details, as well as the application of BPM patterns and practices in industry with special emphasis on financial institutions such as banks. Before, during and after the implementation of any of the processes, very important things that will be briefly described and presented in this paper are preparing the ingredients for a successful BPM project. According to presented information and experiences, the definition, application and concept of BPM Suite will be presented in the next chapters of this paper in correlation with DMS (document management system) and BI (business intelligence) on a concrete example of Real Banking Payments System.

\section{Definition of Business Processes}

From a pragmatic point of view, business processes describe the way something is being implemented in the organization. However, there is not any unique definition of business process, and it depends on the context it is used in. According to Harrington (1991), Martin (1994) and Davenport (1993), business process is the set of logically related activities, which use the company resources, with the ultimate aim of meeting the customers' needs for the products or services of the appropriate quality and price, within an adequate period, realizing some values at the same time [4]. Business is the system of integrated processes. A critical business advantage is understanding the way of the very business and communication of it among employees, partners, customers and suppliers. The basic characteristics of the business processes are: 
- Every process has a purpose;

- Every process has an owner;

- Every process has the beginning and ending;

- Inputs enter the process unlike outputs;

- Process consists of sequential activities;

- The success of the process is simple to determine, based on inputs and outputs;

- Process is important to have internal and external suppliers and customers in order to exist at all;

- Improvement of the process is inevitable.

Depending on the context, the business process is being mentioned, there are several classifications of the process. Every company represents a special case, and must be viewed through interconnection of business processes and their dimensions. No matter how specific it is or is taught to be, each company has the entire range of mutual process and business dimensions:

- Division according to the organizational structure;

- Division according to the time intervals;

- Division according the territory;

- Division according to the product categories and services;

- Division according to the suppliers and customers.

According to the field of action of the process within the organization, they are divided into three different types [5]:

- Individual processes performed by individuals;

- Vertical (functional) processes which are part of the functional unit or department of organization;
- Horizontal processes which go through several functional units.

Michael E. Porter can be considered the driver of the attention to the business processes, who explained the concept of the company as the value chain in his book: Competitive Advantage: Creating and Sustaining Superior Performance from 1985. The value chain includes more business processes from the development of new product and ordering to the selling to the customer after the completion of the sale. According to Porter, the value chain is consisted of primary and secondary activities (Fig. 1). All secondary activities must be included in a unique value chain. Unlike the primary activities, the secondary ones do not accomplish a direct value for the company, but are important for its functioning. Process is the part of value chain, and depending on complexity, it can be divided into smaller parts, actually sub-processes. For example, procreation is divided into ordering, negotiating, contract, receiving, storage, payment, etc. Activity is the smallest part of the process which is possible to model and display in the diagram. Activity can display a relatively complex work task which is not necessary to examine in more details for the purpose of a particular project; it can also display the simplest operation not possible to further divide, and it is called step [6].

Research shows that the most common difficulties during the introduction of BPM in companies are:

- There are more processes that change at the same time: $42 \%$;

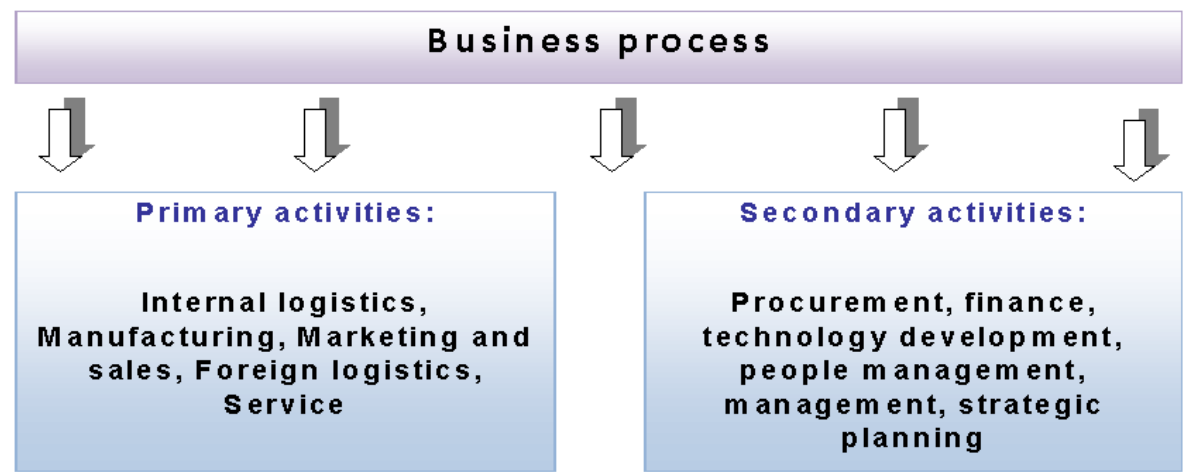

Fig. 1 Division of the business process to activities according to M. Porter. 
- Lack of interest of top management: 37\%;

- Management wants ROI assessment, which is impossible: 23\%;

- Management is not willing to invest: $22 \%$;

- Previous experiences of introducing BPM are not good: $12 \%$;

- Something else: $10 \%$.

- There are five basic objectives BPM should achieve:

- Activity coordination;

- Employee coordination;

- Application system coordination;

- Data coordination;

- Monitoring and controlling.

As a result, BPM enables the standardization through the spreading of wide range of process architecture and formation of business process repositories, and consequently the knowledge management. The most important questions any successfully implemented BPM answers are [7]:

- What happens when the business process is changed?;

- How can be certainly asserted that the observed process is of a good quality?;

- How can we know if a certain business process (usually newly proposed) is in accordance with IT requirements and capabilities, business policy and regulatory conditions?;

- How is it possible to provide a predictable duration of the business process?

Business processes in any complex organization are horizontally and vertically integrated, and their consideration is possible through the creation of the process architecture. Process architecture in a narrow sense represents the highest level of designing the business process within the organization, while in the broader sense represents coherent and detailed description of all operations and activities of the company (multi-level display). One of the main goals of process architecture is to accentuate and to set the main process and sub-processes apart in a specific time, which should be analyzed and eventually implemented, with the aim of achieving a competitive advantage on the one hand, and the customers' satisfaction on the other.

According to all the mentioned in this paper, we choose the payment process which was at the moment the most acceptable for the BPM application. One of the crucial reasons was the huge amount of documentation following this process, which was at the very moment not organized and utterly exposed from the security point of view.

Floods that twice happened in Bosnia and Herzegovina were also one of the reasons for this process to be implemented by using already mentioned technologies. Therefore, the given solution will be presented in next chapters.

\section{Concept of Business Process Management}

Around the world, business is under enormous pressure of great competition, business surrounding that is rapidly changing and demanding customers. Three trends that contribute this pressure are:

- Globalization;

- Technological, legislative and regulatory changes;

- More agile and flexible organizations.

All these pressures made an interest for analyzing of business as more flexible and effective. Each organization is defined with numerous business processes that describe the way of how the organization conducts its business. Some processes are of a great importance for organization business, and make its comparative advantage. Some of them are not so important, but still essential for its functioning. Business processes are, in fact, the nervous system of every company and therefore it is crucial to manage them [8].

Business Process Management combines management approach with the appropriate technology in order to improve the performance of the company. Business process management is actually a 
systematic approach of business improvement based on design, measurement, analysis, improvement and managing of the processes. Business process management relies on business approach of changes managing, because of the business processes improvement, with the ultimate aspiration for achieving business goals. These changes include the entire life cycle of the process: from the modeling and defining to its implementation, analysis and process optimization (Fig. 2).

The first step in the business process management is the definition (vision and design) of business processes. The owners of business processes in this stage have the most important role, because they have the business requirements and available resources. The next stage is business process modeling, which includes collecting enough details in order to understand the functioning of the process. Then, the very course of the process is being formalized by using the business processes course diagram. Then, the business process is being implemented and carried out within the company, while KPI (key performance indicators) are being monitored [9]. The collected data are being analyzed in order to identify an unexpected behavior, non-optimized courses and bottlenecks, and are optimized on the basis of that process.

- By managing of the business processes, these are achieved:

- Better quality;

- Shorter time;

- Lower costs;

- Improving;

- Reduced business risk.

Nowadays, the very concept of business process management is an integral part of every organization which strives to become and remain competitive. The most successful companies in the world are such, thanks to their practice of business processes management. BPM improves the competitiveness and the degree of company innovation, and brings to faster and more flexible reactions of the company to changing market conditions. Modeling tools, implementation and monitoring of business processes are business solutions used by managers, IT specialists, analysts and users in order to create models of business process in the organization, store information about these models and analyze them. In terms of functionality, these tools provide documenting

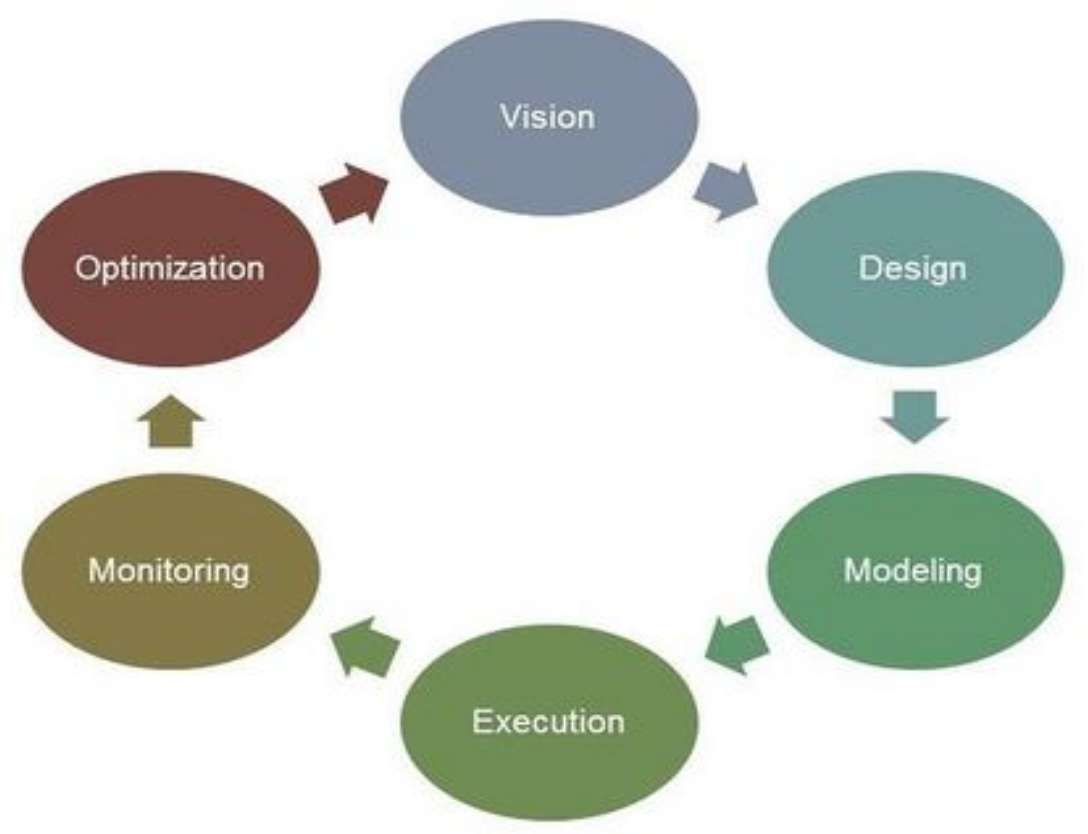

Fig. 2 The life cycle of business process management. 
and analysis of the existing situation, as well as documentation of proposals for improvement and the analysis of the expected effects of the proposed changes. A great offer of tools for modeling business processes in the market of software products is the result of the interest for this region for the last ten years. Intense competition of manufactures of tool for modeling business processes enables potential customers a great offer, but at the same time raises a question of selection of the best software tool. Therefore it is necessary to define, systematize and analyze characteristics of software tools in this region.

During the selection of the tools for business processes modeling, it is important to carefully consider their capabilities and compare them with the objectives of the project. The reports of the consulting companies (such as Gartner, Business Process Trends, B.P. Management Initiative, etc.) can be used for this purpose, or some of the methods for multiple-criteria deciding. In decision-making process, first it is important to set the criteria (tools features), which are important for achieving the objectives of the project, and then to assess the level of functionality of certain tools concerning the defined criteria. Currently in the world market, only Oracle BPMS provides the possibility of performing modeling and analyzing of business processes through unique surrounding, as well as simulation implementation, setting into executive surrounding and monitoring of business processes in real time. Since the bank possessed necessary licenses for a given tool, it would be logical to use it for the needs of business process realization, which will be explained in details later.

\section{BPM in Real Banking Payments System}

In modern business, documentation is getting more important part of every system. Therefore, their security is of crucial importance, and it should never be allowed to be kept only in paper form. This fact was the main reason for the development of non-paper business process of Banking Payment System in one large bank in Bosnia and Herzegovina.

There are numerous flaws in business that are using physical documents rather than their electronic version: large archives exposed to the risk of deterioration due to natural disasters and/or unprofessional human activities and their handling, lack of version control, extremely small data security, poor control and monitoring, required human resources. Business processes with the flowing of documents are certainly one of the most frequent encountered types.

The payment system was the key process, which was at certain moment of primary interest. Four groups of users worked on the analysis and development of it: Business Users, IT, End Users and Process Owners (Fig. 3).

Each of these users group has done its part of the job, and they got TO-BE optimized form of the very process through several iterations based on AS-IS. During the analysis and modeling that process, all the knowledge and mechanisms were used as already described in previous chapters of this paper. The final and optimized shape of the realized process is shown in Fig. 4.

For better understanding of the implemented process, we will briefly describe it. It is consisted out of seven steps (swim lanes): scanning, processing (metadata input), control, modification, payment and copying of data to the central banking system, correction of eventual mistakes during the payment and copying, and possibility of rejecting orders any of early mentioned steps. It is important to say that the very process is integrated with Abbyy OCR (Optical Character Recognition) tool for the automatic analysis of scanned documents, as well as recognition and adding of metadata that describe the very document. Apart from Abbyy OCR tool, there is also an internal mechanism for creating and using preinstalled templates, as well as Oracle Full Text Search possibility, performing the conversion of nearly 400 types of formats in the form suitable for its manipulation and searching. 


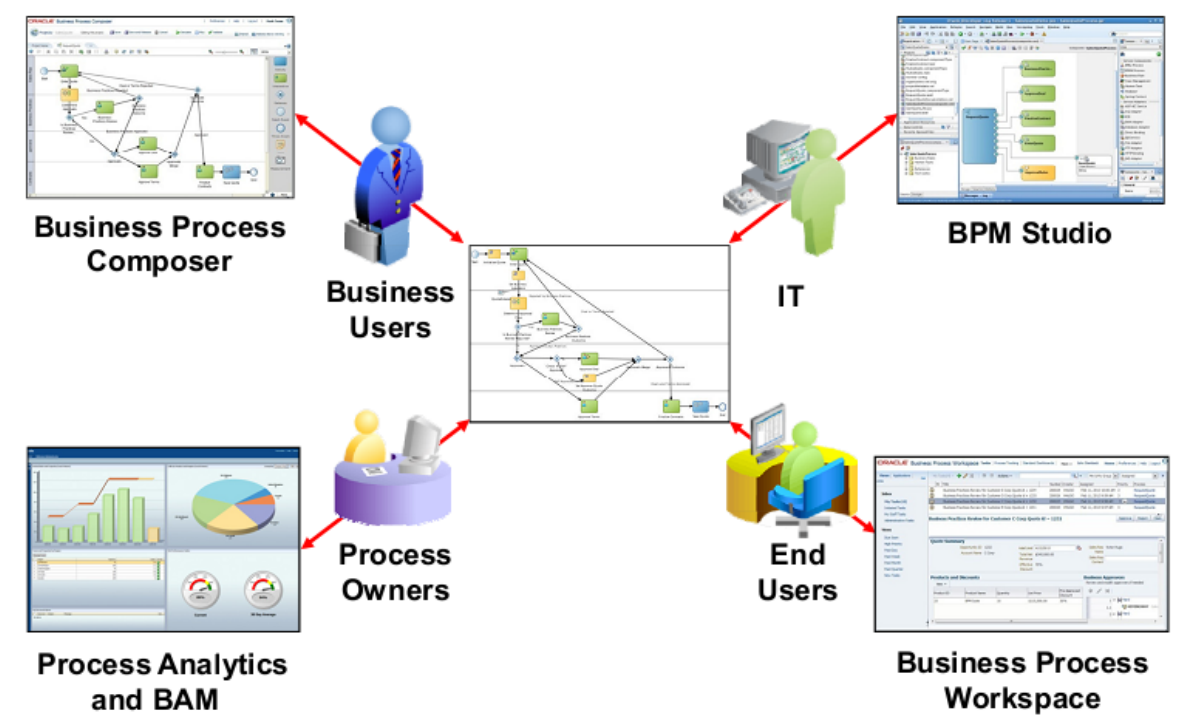

Fig. 3 Collaborative users work.

For the realization, analysis and monitoring of this process, several tools efficiently harmonizes and characterizes were used. The following Oracle technologies were used:

- DMS with its subsystems Web Center Capture, Web Center Content and Custom ADF (Application Development Framework) Applications;

- BPM with its subsystems BPM Composer/BPM Studio, BPM Workspace and BAM;

- Reporting Tools such as BI, Custom reports, etc.

The solutions are completely web-based, so that users aside from the web browser do not need any additional configurations or installations. Special attention was paid to the user's interface and the image of the very forms. One such form is shown in Fig. 5.

The design of the user's interface required a detailed analysis, and numerous testings' show that the best solution is that image of the money order is on the left side of the screen, while the metadata describing that money order is on the right. Warnings and other information the user has to pay attention are marked with different color and larger font of the letters in order to be better noticed. Aside from the user's interface, it is important to pay attention to system stability, the speed of response and data processing, since this is one of the most important banking systems. For the first half of the year of application of this system, more then million money orders have been scanned and processed, and the average speed of processing of one money order (from the scanning to the payment) is 38.7 seconds in the case of manual processing and input of metadata for money orders not electronically filled in, and 12.3 seconds for electronically filled in data OCR mechanism is applied on. According to these facts, the system more than meets all the needs of the institution which it is used in (aside from the security aspect).

Every process, including this one, is implemented as already described in order to process owners would have real-time insight in each part of the process. This can prevent all the difficulties in the area of payment system in the vary bank, and eventually, if necessary take certain measures not to ever have them. During the analysis of business process and before its implementation, it is possible to identify specific bottlenecks in the process, and then optimize it. Simulators are used for such purposes. The more realistic and accurate simulation parameters, the more reliable results are. After the implementation, real-time monitoring of such a designed process is carried out by using BAM. BAM allows monitoring of 


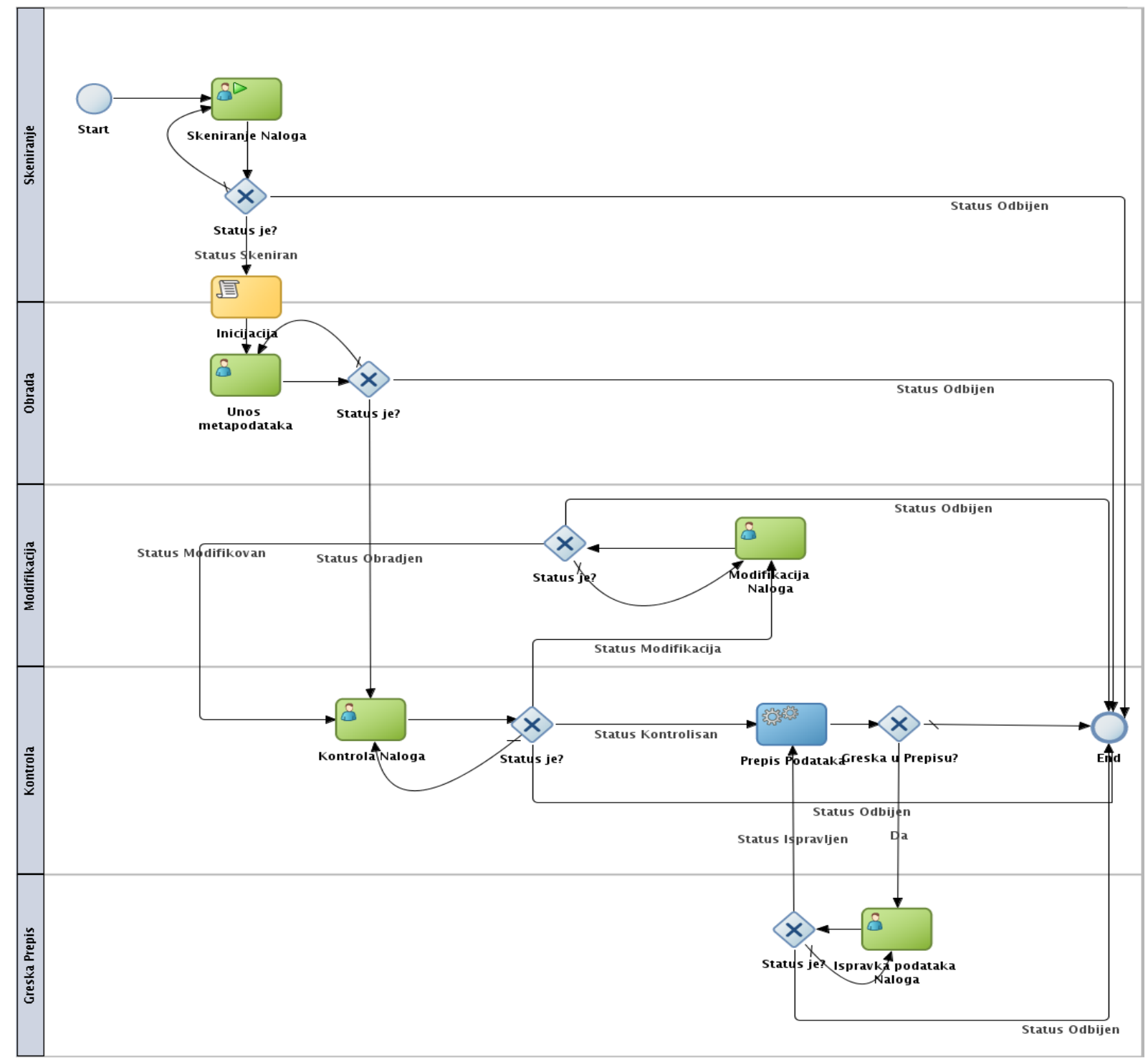

Fig. 4 Realized Banking Payments System.

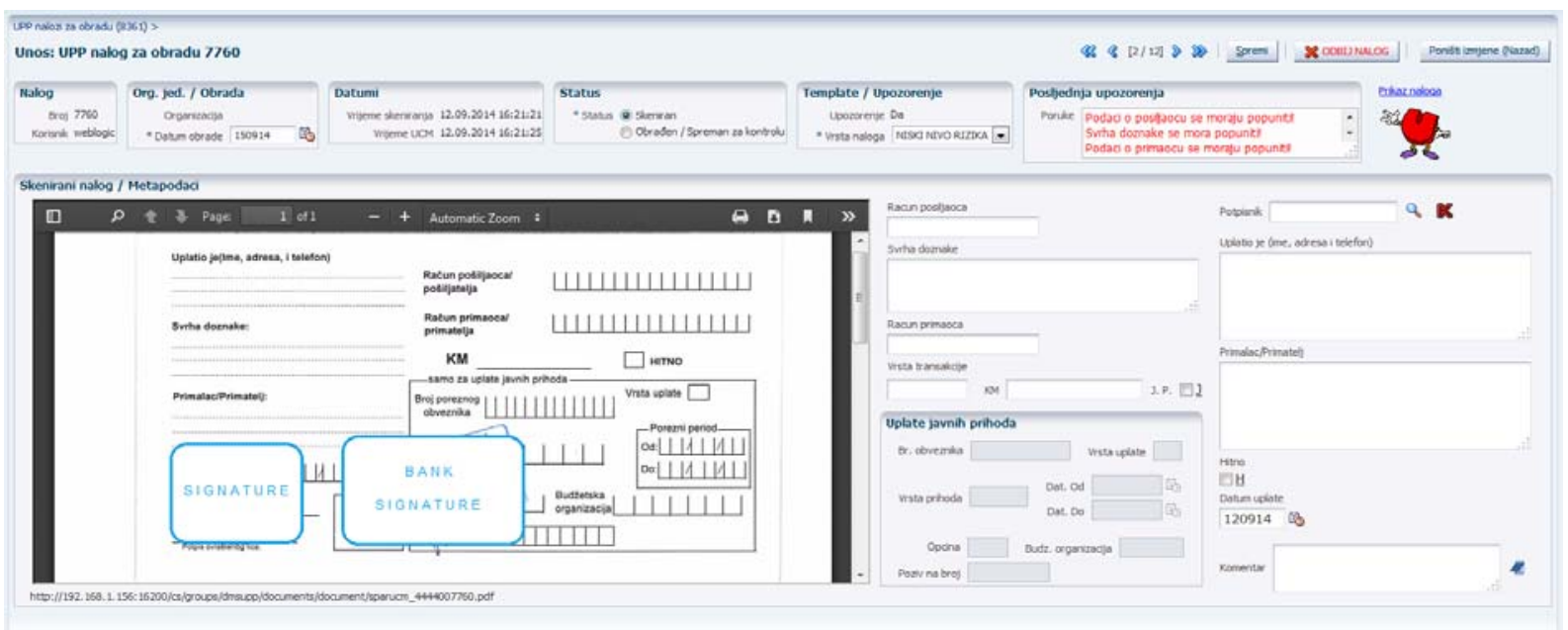

Fig. 5 User interface. 


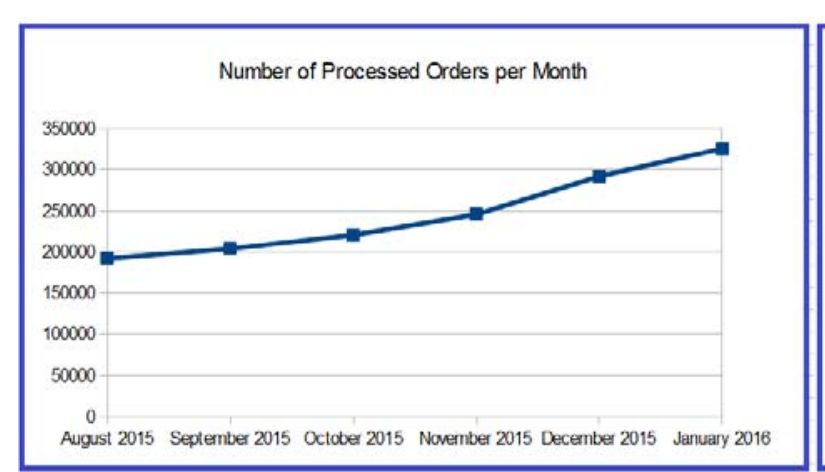

Fig. 6 Financial and effectiveness results.

every running instance of the process in real time with the additional possibility of creating alerts in the case some indicator (KPI) reaches a defined level. Oracle BPM also provides process star schema views. These provide access to the BPM Process Cubes data and can be used by any external BI tool for analysis and reporting purposes or by predefined BPM Workspace reports. This fact gives the full strength to such a realized system.

The real figures indicate that the number of money orders in one month being processed before this system, is even 3 times lower, relating to the current number of monthly processed money orders. If we add a fact such a result needs about $14 \%$ less of human resources, then we can realize a complete financial profitability.

Fig. 6 shows the comparative overview of the processed money orders in the last 6 months (left graph) and the average number of working hours (per working day) of the employees who worked on the processing of these money orders in the same period. It is clear that the number of processed money orders drastically increases from month to month (in the last 6 months, the number of money orders almost doubled) while the growth requires less working time of the workers. Therefore, the system justified all the initial expectations, both financially and efficiently, the number of processed orders, speed of the order processing, which significantly improved the competitive position of the bank in this business area, relating to competitors. Detailed analysis, design and proper application of such systems on the basis of all indicators are definitely a way to success.

\section{Conclusion}

The next generation of business process management is here. The constraints have been removed providing BPM without barriers. Oracle BPMS simplifies achieving process management success by delivering a unified and complete solution for all types of processes. Business Process Management is a proven, practical approach for bridging the strategy-execution gap and driving business value in the following ways:

- Efficiency through productivity gains and reduction in operational and change costs arising from duplication of time and effort;

- Visibility by harmonizing concept-to-market, sales and customer service processes, thereby improving customer acquisition, wallet-share and retention;

- Agility by accelerating time-to-market and time-to-compliance with both industry standards and regulatory requirements.

The first BPM project an organization undertakes can be critical. Given that there may not be either the time or willingness in the organization to engage in the broader process improvement and enterprise-wide value-chain analysis that often accompanies BPM, means that an initial project often has to demonstrate value with limited resourcing, with the validity of BPM as an approach hanging on the outcome. A successful proof of concept will effectively demonstrate the benefits of BPM, empowered by the adoption of a BPM suite: the deployment of a 
common language by which the business can understand and define its processes; a means of more closely aligning business needs with their enabling technologies; flexibility with regards to process change and agility in responding to changing business requirements; live and up-to-date performance data, enabling effective performance management and appropriately targeted process improvement. That means IT leaders should be prepared to run a BPM project as a proof of concept which show demonstrable benefits within a tight timeframe in order to achieve continuing business buy-in. These constraints highlight the necessity of carefully selecting the right process, approach and resources to deliver as a proof of concept.

Throughout the project there needs to be a constant dialogue between the process delivery team and identified stakeholders to ensure the solution is fit for purpose and that expectations are managed and aligned throughout changing circumstances and priorities. By following the right recipe, IT can thus ensure that BPM is a dish that the business will want to order more often. The application of these practices proved to be efficient on realized process Paperless Banking Payments System, which justified all the expectations after several months of application and minimize financial performance as well as proportionately increased the very efficiency, effectiveness and security. As a result, the bank became dominant in the market of payment traffic in Bosnia and Herzegovina, which precisely was the wanted road—road to success.

This work presents a successful application of BPM methodology and concepts on one bank example.
Identical procedure could be applied on any other system, even industrial one, in any company and organization. Time, cost and human resources results will be successful as in mentioned example in any system.

\section{References}

[1] Aalst van der, W. M. P., Hofstede ter, A. H. M., and Weske, M. 2003. "Business Process Management: A survey.” In Proc. Business Process Management: International Conference, BPM 2003, June 26-27, Eindhoven, the Netherlands, ser. LNCS. Springer, pp. 1-12.

[2] McCormack, K. P., and Johnson, W. C. 2001. Business Process Orientation: Gaining the E-Business Competitive Advantage. New York: St. Lucie Press.

[3] Vuksic, B., Hernaus, T., and Kovacic, A. 2008. Upravljanje Poslovnim Procesima-Organizacijski i Informacijski Pristup. Zagreb: Skolska knjiga.

[4] Vuksic, B., and Kovacic, A. 2005. Upravljanje Poslovnim Procesima. Zagreb: Sinergija-nakladnistvo d.o.o., 2004.

[5] Lagunda, M., and Marklund, J. 2013. Business Process Modelling, Simulation and Design. New Jersey: Pearson Prentica Hall.

[6] Vuksic, B., and Kovacic, A. 2004. Upravljanje Poslovnim Procesima. Zagreb: Sinergija-nakladnistvo d.o.o., 2004.

[7] Dumas, M., Rosa, M. L., Mendling, J., and Reijers, H. A. 2013. Fundamentals of Business Process Management. New York: Springer.

[8] Yimwadsana, B., Chaihirunkarn, C., Jaichoom, A., and Thawornchak, A. 2011. "DocFlow: An Integrated Document Workflow for Business Process Management.” Interntaional Journal of Digital Information and Wireless Communications (IJDIWC): 219-29.

[9] Pho, H. T., and Tambo, T. 2014. "Integrated Management Systems and Workflow-Based Electronic Document Management: An Empirical Study.” Journal of Industrial Engineering and Management (JIEM): 194-217. 